\title{
ELEMENTOS DOCTRINALES PARA EL ESTUDIO DE LA ARGUMENTACIÓN COMO EJE DEL CONTROL JUDICIAL
}

\section{Iván Vargas-Chaves*}

Fecha de recibido: 25 de septiembre de 2013

Fecha de aprobado: 17 de octubre de 2013

Artículo de reflexión

Forma de citación: Elementos doctrinales para el estudio de la argumentación como eje del control judicial. Revista Prolegómenos. Derechos y Valores, 16, 32, 235-246.

\section{Resumen}

En el presente artículo se examinan varias propuestas que abordan la argumentación como un ejercicio válido y necesario de control judicial; ello, a través del estudio de diversos elementos doctrinales, como lo son la representación democrática argumentativa, la interpretación previa y la debida justificación de las decisiones, así como la ponderación y la aplicación de los principios, entre otros. Al margen de lo anterior, nuestra intención no es otra sino la de presentar una descripción del estado del arte de dichas cuestiones, el cual es presentado en un repaso detallado en varios planteamientos teóricos que, directa o indirectamente, evalúan el papel de la argumentación como eje del control judicial.

\section{Palabras clave}

Argumentación, control judicial, democracia argumentativa, interpretación, ponderación, principios.

\section{DOCTRINAL ELEMENTS FOR THE STUDY OF ARGUMENT AS A PILLAR OF JUDICIAL CONTROL}

\begin{abstract}
This article evaluates several proposals about the argumentation as a necessary requirement in any exercise of judicial review. The proposals are analysed through many doctrinal approaches. For instance, the argumentative democracy; the interpretation and the justification of the
\end{abstract}

Abogado de la Universidad del Rosario; magíster (cand.) en Derecho de la Universidad de Génova; magíster en Derecho Privado de las Universidades de Salamanca y Pública de Navarra en convenio con la Universidad de Venecia - Ca' Foscari. Doctorando en Derecho en la Universidad de Barcelona. Visiting scholar del Institute of European and Comprative Private (2012), así como profesor e investigador invitado en universidades de México, Italia y España. Correo electrónico: ivan@ vargas.com.co. El autor agradece de manera especial al Prof. Dr. Martín Juárez-Ferrer (Universidad Nacional de Córdoba, Argentina) por sus pertinentes observaciones y sugerencias, las cuales contribuyeron al resultado final del presente artículo. 
decisions; the balancing and the principles. Our intention in this study is neither to analyze some problems and its solutions; rather, it is to present the state of the art in several theories about the role of argumentation in the context of judicial review.

\title{
Keywords
}

Argumentation, Argumentative Democracy, Balancing, Judicial Review, Principles, Interpretation.

\section{ELEMENTOS DOUTRINAIS PARA O ESTUDO DA ARGUMENTAÇÃO COMO EIXO CONTROLE JUDICIAL}

\begin{abstract}
Resumo
Neste artigo várias propostas que abordam o argumento como um controle judicial válida e necessária de exercício é discutido e, portanto, através do estudo de vários elementos doutrinários, como representação democrática argumentativa, a interpretação anterior e justificação adequada decisões, bem como do peso e da aplicação dos princípios, entre outros. Para além do referido, a nossa intenção é apenas apresentar uma descrição do estado da arte dessas questões, que é apresentado em detalhes em várias abordagens revisão teórico que direta ou indiretamente avaliar o papel da argumentação no centro do controle judicial.
\end{abstract}

\section{Palavras-chave}

Argumento, controle judicial, argumentativos democracia princípios de ponderação de renderização

\section{A MANERA DE PLANTEAMIENTO INTRODUCTORIO}

Asumir que la argumentación constitucional tiene la función de limitar el ejercicio del poder de los jueces puede resultar una postura demodé, ya que al hacerlo, se está también asumiendo una postura similar a la de la Revolución Francesa en relación a la judicatura, que habiendo reemplazado los jueces del Ancien Regime, requirió de los nuevos el ser tan solo la bouche de la loi, limitando su función a la de meros aplicadores mecánicos de la ley ${ }^{1}$.

1 En este sentido, Vigo asevera que la argumentación constitucional es la matriz de todo tipo de argumentación jurídica, al estar ésta planteada desde una sistematización. Véase Vigo (2009, p. 219). Esto puede llevar a muchos, como es el caso de Tushnet, a pensar que puede llegar a sustituir el buen razonamiento de aquellos jueces que no tienen la experiencia relevante en asuntos de política nacional, para fundamentar sus
La labor argumentativa de un juez consiste en estructurar sentencias a través de razones que favorezcan una o varias ${ }^{2}$ ratio decidendi capaces de sustentarlas. Es una labor que puede llegar a ser muy compleja en la medida en que el sistema jurídico dado plantee la utilización de distintas fuentes del derecho, punto hacia el cual existe una tendencia a nivel mundial, los cuales, eventualmente pueden estar incluso conectados entre sí de muy variadas formas (Atienza, pp. 47-96) . De allí que el mérito en el quehacer del juez que argumenta será el lograr

fallos correctamente, y por lo tanto, no tendrán la habilidad para satisfacer las expectativas que la sociedad tiene sobre ellos (1992, p. 762).

2 Debemos recordar que no necesariamente una sentencia puede llegar a tener una razón de la decisión (ratio decidendi), como ocurrió en Marbury v. Madison, donde además de resolverse el problema jurídico planteado por el tribunal, que hacía alusión a si era o no posible revocar el nombramiento de un juez de paz, se resolvió también la aplicación de la constitución sobre la ley. 
reordenar toda la masa normativa, doctrinal y jurisprudencial en un caso, así como su acervo probatorio, de forma tal que pueda satisfacer las expectativas de la sociedad.

Por otra parte, sobre la idoneidad de quienes ocupan tal cargo cabe la siguiente pregunta: ipuede acaso un juez, como persona de buen juicio que se supone que debe ser, tener esta destreza sin haber ocupado previamente algún cargo de gestión de asuntos de índole pública? Parece ser que para Tushnet hay un NO rotundo, cuando contradice el planteamiento de Frankfurter (1992, p. 756), ya que ante todo buen juicio debe prevalecer la experiencia, quedando únicamente la argumentación como sistema que limita el ejercicio de los poderes judiciales. En efecto, si los jueces pudiesen aplicar a discreción el criterio que consideren mejor conveniente para las circunstancias de cada caso, la argumentación utilizada entonces carecería de reglas que sirvieran para distinguir los razonamientos correctos de los que no lo son (Bouzat, 1998).

Y es en este escenario donde criterios como la ponderación basada en una teoría discursiva del constitucionalismo -que logre integrar los principios construidos del constitucionalismo contemporáneo- adquiere un gran protagonismo. Así, Alexy propone una estructura que teniendo de frente el concepto de equilibrio, es capaz de armonizarse en una argumentación racional y objetiva que permita la construcción de sentencias que sean aceptadas a largo plazo como razones de corrección. Es importante ver que esta aceptación se logra a través de argumentos correctos o razonables y, con la existencia de personas racionales que tengan la disposición y capacidad de aceptar estos argumentos, si y sólo si, estos son correctos o razonables.

En cualquier caso, y luego de resaltar en este primer apartado la importancia de la argumentación, somos conscientes que los elementos doctrinales presentados en un ejercicio de este tipo estarán siempre incompletos, o por lo me- nos serán discutibles en un entorno doctrinal constantemente oscilante; de allí por ejemplo la ausencia de conclusiones en este artículo. No en vano, esperamos que lo aquí desplegado, sea útil en el enfoque de las discusiones acerca de cómo la argumentación -desde una óptica constitucional- debe marcar efectivamente la pauta en el quehacer de todo juez.

\section{DE LA LEGITIMIDAD A LA REPRESENTACIÓN ARGUMENTATIVA}

No existe un poder legítimo en sí, afirma Duverger: hay, en cambio, poderes que se consideran a sí mismos como legítimos (Duverger, 1970, p.10). En efecto, los jueces al tener la posibilidad de asumir que todos los fallos proyectados gozarán de la legitimidad en su fuerza vinculante, podrían llegar a fallar en función de sus intereses propios o ambiciones, y esto es una preocupación que Tushnet trae a colación a través de Madison en el principio republicano, en tanto en cuanto este «(...) enables the majority to defeat [the] sinister views [of a minority] by regular vote» (Madison, 1961, p. 308), a la vez que formula una recepción de las teorías de la interpretación como pautas limitadoras de la función de los jueces.

Con todo y ello, Tushnet expone la problemática de la falta de motivación verdadera de las sentencias por parte de jueces norteamericanos, trayendo a consideración el caso de City of Richmond v. J.A. Croson Co, en el que el juez O'Connor al citar la teoría de la representación de a Hart, lo hizo más a manera de adorno que como parte central de la ratio decidendi, ante lo que válidamente Tushnet se pregunta ¿si la teoría constitucional no sirve para motivar las decisiones, entonces cuál es su papel?, y añade, es claro que esta pregunta no puede ser contestada por los jueces, ya que «most opinions are now drafted by law clerks».

En este sentido, Bouzat, al estudiar el caso argentino, arremete contra el control constitucional preventivo y abstracto, pues este se traduce 
en una resignación del poder legislativo frente al judicial, en donde hay una suerte de elitismo que presupone que aquel reducido grupo de magistrados están mejor capacitados que los parlamentarios para la solución de los conflictos valorativos que se plantean para la declaratoria de inconstitucional de una ley ${ }^{3}$.

Debemos, entonces, regresar a la argumentación constitucional, la cual por el solo hecho de trabajar con principios, parece suponer en palabras de Atienza «siempre de una u otra forma, una operación de ponderación (bien la realización de una ponderación, o bien la aceptación de una ponderación efectuada anteriormente) (2011, p. 50), el problema entonces estará en "cómo determinar el peso de las diversas razones en presencia» siguiendo esta misma línea argumentativa, que concluye con otra pregunta: ¿cabe al menos establecer alguna jerarquía sobre los tipos de razones presentes en los procesos de justificación? Así, pues, podemos considerar a la argumentación constitucional como aquella enfocada a proveer las herramientas necesarias para justificar todos los procesos que conlleven la labor de interpretar y aplicar la Constitución sobre las normas cuestionadas.

Retomando el planteamiento alexiano (Vigo, 2003, pp. 203-224) de la representación argumentativa ${ }^{4}$, cabe también concebir una relación

3 Y es que los parlamentarios han de contar con una comisión especializada en asuntos constitucionales, que deberá evaluar la constitucionalidad de los proyectos de ley antes y durante los debates, pero si, y solo si un ciudadano se llegase a sentir afectado por una ley no elaborada acorde a la constitución, entonces este podría recurrir al control de constitucionalidad, ello se explica en aquella postura de Mill que expone que no hay mejor juez que uno mismo para sus propios intereses. Aunque se tenga en cuenta la anterior apreciación a efectos de nutrir este debate, debe así mismo tenerse en cuenta la compatibilidad entre las teorías del derecho, de la interpretación constitucional y de la legitimación, con miras a estructurar una sólida teoría de la democracia

4 Vale la pena no dejar de omitir la distinción de representación argumentativa, en cabeza de los jueces constitucionales, y de representación decisiva -y de igual forma argumentativa o discursiva- en cabeza de los parlamentarios. entre el pueblo y los miembros de los tribunales jurisdiccionales de cierre, en la cual confluyen tanto los argumentos jurisprudenciales, como las decisiones plasmadas en el voto para elegir al parlamento, encargado a su vez de la elección de dichos miembros. Esta concepción no es otra que la de un modelo deliberativo de democracia, a través del cual los ciudadanos estarán en todo su derecho de exigirles a los magistrados el cumplimiento de un deber de institucionalizar su discurso con argumentos racionales, como medida para la toma de decisiones a través del sentido dado a los fallos.

Debe, pues, haber armonía, una relación de complemento entre parlamentarios y jueces constitucionales, ya que estos últimos para crear una justificación válida en sus decisiones judiciales deberán apelar a los mismos valores y presupuestos que justifican una democracia para la que trabajan conjuntamente. De esta manera, no cabrán erróneas percepciones acerca de si estos imponen o no imponen su voluntad, promoviendo, por el contrario, valores que justifiquen cualquier decisión democrática frente a situaciones concretas, en las cuales las normas pueden resultar atentatorias contra los propios presupuestos que las legitiman.

El precedente tampoco deberá ser ajeno a la argumentación constitucional, toda vez que un juez al emitir un fallo con fundamento en la forma en que los demás jueces lo hicieron en el pasado, estará respetando la igualdad en la aplicación jurídica, una igualdad que se enmarca en la Constitución y que, insistimos, le da cimientos a la argumentación constitucional. Este respeto por los precedentes se convertirá en certeza jurídica y, consecuentemente, en la materialización de la confianza que los ciudadanos depositamos en el Estado, una confianza que nos genera estabilidad en las regulaciones ${ }^{5}$.

De allí parte la necesidad propia de darle una fuerza vinculante al precedente, al satisfacer, de esta forma, las expectativas que como sociedad tenemos y que, por ejemplo, Tushnet pasa en alto al referirse al aparato jurisdiccional. 
Por último, atendiendo a la cuestión sobre cómo es posible reforzar esta satisfacción de expectativas, podemos valernos de la construcción de líneas jurisprudenciales que revistan de coherencia a los fallos. Todo ello nos llevará a un contexto ideal en donde los jueces tengan la suficiente confianza para emitir sus propios juicios, valiéndose de la argumentación constitucional, pero ante todo generando la aceptación de personas razonables a través de argumentos razonables.

\section{LA JUSTIFICACIÓN DEL CONTROL JUDICIAL}

Tushnet, al analizar las formas alternativas de control judicial, (2003, pp. 2781-2802), toma como punto de partida lo que él mismo denomina weak-form systems o formas débiles (Landau, 2011, p. 29), un método concebido para el cumplimiento de los derechos de segunda generación, a través de la limitación del poder de los tribunales para invalidar la legislación, luego de una evaluación que determina si esta es acorde o no a la Constitución. En contraposición, se encuentran los strong-form systems o formas fuertes, a través de los cuales se adquiere la competencia general para determinar el alcance y significado de la Constitución.

Son dos esquemas de control que han sido objeto de un juicioso estudio por parte de la doctrina, que ha tratado de responder la cuestión referente a los criterios que establecen en qué casos deben los legisladores y tribunales aplicar uno u otro. En este análisis, este autor, además, considera el control judicial de tutela o thayeriana, como la vía a seguir cuando los tribunales detecten un error ${ }^{6}$ en el quehacer del legislador, esto es, al promulgar una ley que va en contra de la Constitución (Tushnet, 2003, p. 2781). La

6 No obstante lo anterior, por ejemplo, las interpretaciones constitucionales sobre materias disciplinarias que el legislador hacen de sus propios privilegios gozan de la presunción de «que éste conoce bien lo que requiere para ajustar su actividad a los fines que la Constitución le establece» (Matheus, 2011, p. 175; Tushnet, 2001, p. 1395). importancia de estas dos formas radica en un diseño constitucional capaz de responder a los retos planteados en una democracia de pesos y contrapesos.

Si bien, el control judicial puede ser necesario para garantizar que el legislador -por la vía ordinaria- no modifique o no vaya en contra de la Constitución, se hacen también necesarios mecanismos para que el control efectuado por los jueces en sí sea controlado o revisado a través de un esquema fuerte (2003, p. 2802), tal y como lo propone Tushnet. Tampoco debe dejarse a un lado el contrapeso que sobre la rama judicial recae, de hecho basta tan solo con remitirnos a Landau ${ }^{7}$ en ese sentido, pues al reflexionar acerca de las credenciales democráticas del poder legislativo sostiene (2011, p. 23) que desde hace tiempo la teoría constitucional estadounidense ha considerado que dichas credenciales son una razón suficiente para también limitar a los tribunales.

Así, una apropiada justificación de la revisión deberá responder a la cuestión del equilibrio entre cortes y parlamento. No en vano Tushnet sugiere que las estrategias de asignación de cualquiera de las formas de control, pueden llegar a ser inestables per se (Tushnet, 2003, p. 2802). Empero, si a consciencia se diseñan estrategias basadas en lo anterior, y si la argumentación allí desarrollada busca -con experiencia y con temperamento judicial- la satisfacción de las expectativas que la sociedad pone en dicho quehacer, entonces la misión se estará cumpliendo satisfactoriamente.

Lo anterior sin que, de un lado, los jueces terminen convirtiéndose erróneamente en intérpretes supremos de la constitución, reduciendo los incentivos que tendrían otros actores frente

Landau considera que en un nivel más básico, los reclamos de atención judicial hacia las instituciones legislativas -si los asuntos se enmarcan o no en términos constitucionales- se basan en ideas acerca de la legitimidad democrática y la mayor capacidad de la rama legislativa, en un amplio espectro de funciones, que van desde la recopilación de información hasta el diseño de políticas públicas (2011, p. 23). 
a la Constitución (Landau, 2011, p. 20), y del otro lado, sin que, por ejemplo, se fuerce al legislativo a aprobar a favor del poder ejecutivo la concentración de más funciones de las que constitucionalmente están permitidas en estados de excepción (Landau, p. 30). A partir de lo anteriormente expuesto, es posible, entonces, analizar el rol de la democracia en la justificación del control judicial.

Dworkin ha escrito al respecto, partiendo de la injusticia de no permitírsele a una mayoría política tomar decisiones, aun cuando existan razones contrarias lo suficientemente fuertes (Dworkin, 2004, p. 22; Hongju-Koh, Harold \& Slye, 2004), de allí que dicho control necesariamente va a comprometer a la democracia ${ }^{8}$. Por otra parte, al analizar la justificación de las decisiones colectivas, Etchichury reconoce que Dworkin «repasa el argumento utilitarista, en el que el número de personas que prefieran algo y la intensidad de esas preferencias constituyen la base de una decisión aceptable» (Etchichury, 2011, p. 38), esto permite entender «que las preferencias no pueden simplemente sumarse, pues en muchos casos, ellas se basan no en lo que alguien quiere para sí, sino para otros» (2011, p. 38).

Esto nos lleva a una lectura comunal de las decisiones, en vez de un ejercicio que únicamente tome la estadística del gobierno por el pueblo9. Lo anterior, encuentra sentido en las implicaciones que tienen las lecturas comunales en un estado democrático, ya que allí la libertad positiva se traduce en el gobierno del pueblo para el pueblo, y sobre todo para sus

8 De la misma forma Dworkin va a sugerir que las preguntas centrales que debe hacerse la teoría constitucional son: ¿Este compromiso está justificado?, y de ser así, ¿bajo qué supuestos? o lo que es lo mismo ¿cuándo?

9 Dworkin añade: «En la lectura estadística, el control individual acerca de las decisiones colectivas que afectan su vida es medido por el poder, de uno mismo, para influenciar el resultado, y en una democracia el poder de cualquier individuo sobre las decisiones nacionales es tan pequeño que las constricciones constitucionales no pueden ser consideradas como para disminuirlo lo suficiente para contar como objetable por esa razón» (p. 29). oficiales (Dworkin, p. 29), sin que ello implique cualquier relación entre gobierno y ciudadanía como colectividad. Tal situación permite concluir que en todo proceso argumentativo y justificativo del control judicial, las preferencias individuales basadas en prejuicios no tienen ninguna cabida, ya que a través de la mencionada estadística se podrían, incluso, llegar a vulnerar derechos tales como la igualdad ${ }^{10}$.

Ahora bien, retomando la estrategia de la asignación de formas de control de Tushnet, podemos afirmar que a pesar de ser inestables, pueden llegar a ser efectivas si son pensadas para cada caso en concreto, logrando inclusive ser capaces de dotar a los tribunales de las herramientas para resolver cuestiones polémicas, y de devolver la autonomía en las áreas sujetas a la forma-débil de control (Tushnet, 2003, p. 2802). Esto último, en un panorama en el que a menudo el pueblo pierde capacidad de autogobierno ante los tribunales, como consecuencia del ejercicio de la forma-fuerte de control judicial (Tushnet, 2003, p. 2784).

Dentro de toda esta línea argumentativa, nos debe quedar por lo menos una primera conclusión, y es que los diseños constitucionales deben ser fiel reflejo de los valores del pueblo, y no de deseos pasajeros de los actores políticos. Más aun, la tarea de interpretar no se debe detener en una sentencia; por el contrario, es una elaboración colectiva con vocación de permanencia, en la que pueden definirse hitos o puntos, pero nunca la estación final (Etchichury, p. 40). Así, si nos situáramos en un plano temporal, no deberíamos darle rienda suelta ni a la forma de aplicación de la revisión que más tenga aceptación en ese momento, ni mucho menos a las preferencias de un gobierno autori-

10 Aquí Etchichury trae a colación un caso práctico desde la experiencia norteamericana planteado por Dworkin: «este autor afirma que por más que una comunidad blanca tenga intensas preferencias por la segregación racial, éstas se fundan en prejuicios y ello las vuelve violatorias del derecho de la población negra a ser tratada como igual. Por ello, no deberían tomarse en cuenta al momento de valorar la voluntad común». (Dworkin, 1993, p. 38). 
tario de turno, para citar tan sólo dos ejemplos. Creemos, al igual que Gargarella y Friedman que la función del control judicial debe ser el fomento del diálogo social ${ }^{11}$, a través de valores que deben ser forjados, luego de un serio y profundo debate deliberativo.

\section{LA INTERPRETACIÓN CONSTITUCIONAL: DOS PROPUESTAS DE ANÁLISIS}

Si intentásemos buscar una aproximación al concepto y real alcance de la interpretación constitucional, nos encontraríamos ante un amplio recital de significados propuestos por diversos autores a partir de la óptica que su respectivo contexto les ha dado. No obstante, hoy por hoy, dos tratadistas, Waluchow (2008) y Berman (2011, pp. 408-420) nos llevan a esta figura a través de un recorrido que analiza desde los métodos que legitiman una determinada interpretación, hasta las diversas teorías que vinculan un destacable número de factores relevantes. Este será el eje que abordaremos para llegar a la relación existente entre dichas teorías y la argumentación constitucional.

Partiendo de una descripción genérica, concebiremos la interpretación constitucional como el quehacer de los jueces y, especialmente, jueces constitucionales, en el que se analizan diversos elementos a la luz de la Carta Política para responder a un determinado planteamiento o pregunta jurídica relevante. Estos elementos analizados suelen ser parte del contexto propio de la jurisdicción del operador u operadores jurídicos. Al margen de esta definición, consideramos oportuno señalar que si estos elementos son analizados desde la argumentación constitucional, podrían también estructurarse como directivas orientadoras para construir el discurso que legitimará la sentencia, apelando a los argumentos disponibles desde toda teoría interpretativa.

11 En este sentido Friedman añade que lo único irónico es que aun aquellos que defienden el control judicial también argumenten que los jueces interfieren con la voluntad popular (Friedman, 2005, p. 171).
En este orden de ideas, si trazásemos la discusión a través de los elementos planteados en esta definición, valdría la pena llegar al alcance que para Waluchow tiene la Constitución frente a la interpretación constitucional, pues en su opinión, las teorías que sobre esta última orbitan están intrínsecamente ligadas a su naturaleza y autoridad como norma de normas, ya que todas contemplan -por lo menos- cuatro elementos comunes, a saber, significado, intención, precedente judicial y teoría (Waluchow, 2009, p. 109). Por su parte, Berman centra el punto de partida de la interpretación constitucional en los enunciados constitucionales, que el juez debe fijar para luego establecer las reglas de decisión a través de doctrines (Alexander, 2011, p. 21), las cuales fundamentan el denominado «nuevo doctrinarismo» (Pulido, 2012, p. 140) y que le permiten al juez constitucional enfocarse en lo que este autor denomina la implementación constitucional (Berman, 2010, pp. 39-69).

\section{LA TAXONOMÍA DE BERMAN Y LAS CINCO TEORÍAS DE WALUCHOW}

Podríamos, entonces, afirmar que esto constituye un notable aporte de Berman, ya que la labor del juez intérprete de la constitución es concebida a través de tres etapas: (i) el establecimiento del alcance del contenido semántico del texto legal; (ii) la determinación de la actividad que rodea dicho contenido, o en otras palabras, la respuesta a la pregunta de ¿̇cuál debe ser la norma aplicable?; y (iii) la adaptación del texto analizado en otras normas jurídicas que sean more easily or cheaply administered, that threaten less overdeterrence, or that are, in any other fashion plausibly thought legitimate, better suited to judicial enforcement (Berman, 2010, pp. 39-69).

No debe, por lo tanto, extrañarnos que, en igual sentido, Waluchow asuma que aquellos casos sometidos a interpretación constitucional deban llevar necesariamente al operador a analizar cuestiones teóricas sobre cuál debe ser 
el enfoque apropiado ${ }^{12}$ para la interpretación de los instrumentos escritos.

En cuanto a las teorías más relevantes, Waluchow identifica cinco, todas ellas compuestas por cuatro elementos o factores claves en común: el significado, la intención, el precedente y la teoría misma. (i) La Teoría Textualista, o teoría del significado original, es aquella que tomando la Constitución como un documento de carácter funcional, propugna por la búsqueda de la intención de los autores de la misma, pues son ellos de quienes deriva la autoridad.

(ii) La Teoría Originalista, o teoría de la intención original, busca en cambio indagar sobre lo cual conjuntamente los autores -el constituyente- querían decir, esto es, responder a la cuestión relativa a la verdadera intención de los constituyentes, para con ello, determinar sus expectativas, o más bien, qué es lo que ellos esperaban lograr al redactar aquello que se redactó en el texto final. La viabilidad de esta propuesta se da en que «después de todo, de los constituyentes se puede presumir que han conocido y tenido en cuenta las entonces normales aplicaciones de las palabras que usaron, y que han pretendido que se alcanzaran sobre los resultados que dicha aplicaciones apuntan, así como los objetivos y valores para cuya realización aquellas aplicaciones parecían las más adecuadas» (Waluchow, 2008, p. 117).

De hecho, la diferencia entre esta teoría y la (iii) Teoría de la Intención Hipotética, está en el futuro plausible o hipotético, toda vez que a pesar de buscar responder la misma pregunta, lo hace desde un escenario ficticio aunque probable, en otras palabras, lo que se quiere descubrir es lo que el constituyente hubiese pretendido plantear en el momento de redacción de la carta política, frente a lo que ahora mismo (en el presente) se toma por certero.

La Teoría Interpretativa de (iv) Dworkin aboga por una interpretación que sea más acorde a

12 Lo anterior, claro está, en atención al papel especial de una Constitución que tanto delimita como limita los poderes que tiene el Estado (Waluchow, 2008, p. 11). los fines preestablecidos por la Constitución, a través de una labor que no se centre en la intención de los constituyentes sino que pondere las consecuencias de tomar cualquier vía interpretativa (Dworkin, p. 214), centrándose más esta teoría en el mayor valor posible que se pueda obtener del tipo de objeto de la interpretación, poniendo a la Constitución bajo «su mejor luz» con la finalidad de indagar acerca de los principios implícitos que le permitirán al intérprete establecer los límites pre-existentes sobre el poder el Estado para desarrollar adecuadamente su quehacer (Waluchow, 2009, p. 126). Dworkin espera, por tanto, que el juez intérprete sea capaz de descubrir alguna razón para elegir preferir una teoría sobre las demás.

Por último está la que Waluchow denomina (v) Teoría Crítica es la que trae consigo múltiples soluciones, las cuales aunque presentan diferentes variantes, tienen en común la intención de derrumbar los mitos que rodean a las «protecciones constitucionales» a través de teorías tales como el entendimiento originario o las intenciones de los constituyentes, entre otras.

Respecto a las críticas que expone de estos planteamientos teóricos, Waluchow empieza por la dificultad que existe en la teoría textualista para afrontar el contenido semántico de las palabras a interpretar, pues estas en si son abstractas y de naturaleza evaluativa, además de llevar no a concepciones sino a meros conceptos, demandándole al intérprete una labor extra de identificación e integración de una teoría adicional capaz de explicar mejor, y de justificar la variedad de inferencias con las que se encontraría el intérprete. En cuanto a la teoría originalista, señala que las intenciones originales son «notoriamente oscuras», por no decir que están sujetas a futuras variaciones y que por sí mismas son indeterminadas completamente, dejándole nuevamente al intérprete la labor de acudir a otros elementos auxiliares.

Siguiendo con su posición crítica a estas teorías, Waluchow se pregunta en atención a la teoría de la intención hipotética: ¿por qué no 
debemos simplemente olvidarnos de este ejercicio hipotético teóricamente sospechoso y tomar nosotros mismos las decisiones? (Waluchow, 2009, p. 126), y respecto a la teoría de interpretativa de Dworkin, nos deja entrever un cuestionamiento acerca de si es conveniente que el juez en su juicio decida «sobre los méritos relativos a las teorías constitucionales rivales acerca de los límites propios de la autoridad del Estado» (Waluchow, 2009, p. 126), pues en su concepción tal juicio es una exigencia que se deriva de la naturaleza misma de la interpretación, siguiendo con su razonamiento. Y es que todo lo anterior es asimilable si entendemos la lógica positivista incluyente de Waluchow ${ }^{13}$ que busca componer una defensa de la justicia constitucional con el fin de superar las deficiencias que en su consideración tiene Dworkin.

Para Berman, si bien el número de teorías de interpretación constitucional es tan amplio como el número de teóricos que las proponen, existen dos grandes grupos, las teorías de enfoque originalista y las que no tienen dicho enfoque. En la primera teoría se da en la labor del juez intérprete una mayor relevancia a las disposiciones de carácter original, respecto a las demás, pues la Constitución, muy a pesar de los años, sigue teniendo el mismo significado desde que se promulgó por primera vez, ello desde el punto de vista semántico, al igual que en la teorías textualista que analizamos previamente. Las variaciones de esta teoría van desde el public meaning que tendría la Constitución razonablemente para una persona de la época en que fue ratificada la norma, hasta el originalismo derivado de la adaptación de la Constitución en administrable legal rules dentro de los límites establecidos por el significado original.

13 Dicha lógica se plantea a través de cuatro premisas: "(a) la determinación y el contenido del derecho dependen de una serie de hechos sociales que, eventualmente, pueden apelar a ciertos estándares morales dotándolos así de validez jurídica; (b) la validez de las normas jurídicas no depende necesariamente de su adecuación a ciertos estándares morales; y (c) en los casos en los que el Derecho apela a la moral no concede a los jueces discrecionalidad para resolver los casos que se les presenten» (De Lora, 2009; Moreso, 2002).
Como crítica a esta corriente, los teóricos de corte no originalista, creen que aun cuando es una teoría interpretativa correcta, no resulta ser del todo una teoría legalmente correcta (Berman, 2010, p. 412). Esta teoría no originalista, por su parte, busca enfocarse en una concepción coherente con los principios democráticos y la soberanía popular, más allá de lo plasmado en la Carta Magna, pues son los intérpretes como operadores jurídicos quienes deben realizar su labor con base a un cuerpo normativo que incluso tenga alcance jurisprudencial. De hecho, si siguiésemos el trasfondo de las críticas de Waluchow, no debería por lo tanto sorprendernos que Berman lo catalogara (2010, p. 416), junto con Strauss, como no-originalista.

Son pues, teorías que buscan analizar elementos a la luz de normas constitucionales para llegar a la solución de casos usualmente difíciles, pero que ante todo, tal y como lo planteamos a la par de la definición de interpretación constitucional, le sirven de cimientos a la argumentación constitucional para justificar el discurso, pues ésta en términos de Prieto-Sanchis «no sólo ha de perfilar los contornos de preceptos abstractos y elásticos, recurriendo desde luego a estándares extra-constitucionales, sino que ha de transitar un largo camino para mostrar el proceso de inferencia que va desde esa norma a la decisión o fallo» (Prieto, 1991, p. 190), pues en el proceso argumentativo para este autor ni la elección de las premisas, ni su contenido, ni la deducción respectiva, son aspectos que se sostienen por sí mismos.

\section{PONDERACIÓN Y PRINCIPIOS}

Para abordar la ponderación como un criterio de argumentación constitucional conviene, ante todo, tener presente la discusión existente en torno al concepto de racionalidad a partir de la argumentación jurídica, y en la no existencia de un consenso sobre cuáles han de ser las condiciones de racionalidad que deben ser satisfechas en cualquier decisión judicial, siendo apenas la fundamentación racional en dere- 
cho la condición que es mejor asimilada por la doctrina. Esto se entiende en la medida en que para ser racional, siguiendo a Bernal, una decisión judicial debe contar con una estructura soportada en términos conceptualmente claros y consistentes (Bernal, p. 60), independientemente de si, por ejemplo, esta fue planteada por varios jueces/magistrados sin un consenso unánime.

En efecto, tanto la precisión conceptual -traducida en claridad- como la consistencia, al ser exigencias de racionalidad en un fallo judicial, lo son también en la labor de ponderación que sobre la misma debió existir en caso de haberse planteado un conflicto de principios constitucionales. La ponderación, además de ser el medio más apropiado para dirimir este tipo de conflictos, quizás el idóneo, es también un método de interpretación sui generis de principios, puesto que como actividad de construcción jurídica centra su labor en extraer aquellas consecuencias jurídicas implícitas de los principios en un caso determinado, en lugar de establecer significados sobre determinadas disposiciones jurídicas.

$Y$ es que al ser muy frecuentes los conflictos entre principios constitucionales es preciso recurrir a los instrumentos que se encuentran ubicados más allá de lo que los constituyentes determinaron, por ejemplo, como lo proponen Atienza y Ruíz-Manero al remitir al intérprete a las razones subyacentes presentes en juicios de valor (Atienza, 2007, p. 25), descartando toda ponderación desde una perspectiva del constitucionalismo de corte positivista ideológi$\mathrm{co}^{14}$, no obstante lo anterior, y sin el ánimo de entrar a este debate, conviene traer a colación (Atienza, 2007, p. 42) algunas cuestiones plan-

14 Tesis argumentada por Paolo Comanducci, quien al sostener que existe una conexión necesaria entre derecho y moral, asume también que existe una obligación de obediencia a la Constitución y las leyes, una ideología que para Atienza y Ruiz-Manero es «criticable y peligrosa pues tiene como consecuencia la disminución del grado de certeza del Derecho derivado de la técnica de "ponderación" de los principios constitucionales y de la interpretación "moral" de la Constitución» (Comanducci, 2003, p. 5). teadas por estos mismos autores en relación a la ponderación y la interpretación ¿̇de qué forma se pueden llegar a relacionar la labor de interpretar con la de ponderar?, si existiese una manera, ¿serían compatibles, o son dos operaciones realmente distintas?, y por último, ¿̇es la interpretación, sencillamente, un tipo o un momento de la ponderación?

Lo cierto es que es necesario contar con un método que sea capaz de poner los principios «de frente» y a la vez de «sopesarlos», lo cual, en términos de Guastini se traduce en establecer una jerarquía de valor a través de juicios comparativos. Se trata, pues, en nuestra consideración, de la ponderación, un método que como lo hemos intentado justificar en párrafos anteriores, responde con un mayor grado de eficacia que otros métodos alternativos a esta problemática, aun cuando el método como tal (la ponderación) no sea del todo aceptado, por ejemplo, por Comanducci quien lo descarta de entrada pues logra un efecto negativo al disminuir el grado de certeza del Derecho ${ }^{15}$.

No obstante lo anterior, y como respuesta a estas críticas, pueden encontrarse métodos integradores de la ponderación, y uno de ellos, compuesto por dos fases, es justamente propuesto por Atienza (2007, p. 46), quien propone aplicar la ponderación convirtiendo de esta forma los principios en reglas, para después, aplicarlas o bien a través de un modelo de argumentación subsuntivo o bien finalista. Por consiguiente, si tratásemos de situar a la ponderación dentro del espectro de la argumentación constitucional, bastaría con hacer una remisión a los tribunales constitucionales, quienes desde

15 Comanducci, (2003, p. 105), quien por cierto al referirse a la ponderación en este mismo texto (p. 107), siguiendo la interpretación de Moreso «añade a su defensa de la certeza que la creación de los principios constitucionales y su modo peculiar de aplicación, la ponderación, a falta de una moral común, aumenta la discrecionalidad de los jueces, que pueden decidir los casos haciendo referencia a las propias, subjetivas, concepciones de la justicia, y también esto, naturalmente, aumenta la discrecionalidad de los jueces y la indeterminación ex ante del derecho» (Moreso, 2003, p.6). 
un punto de vista netamente formal, le dan la importancia necesaria a esta figura respecto a los tribunales ordinarios gracias al rol que los principios allí juegan (Atienza, p. 31).

En ese sentido, Atienza realiza la siguiente aclaración: «(...) no quiere decir que los jueces ordinarios no ponderen, sino que sólo tienen que hacerlo, en cierto modo, cuando se enfrentan con casos difíciles que no pueden resolverse sin remitirse -explícitamente- a principios constitucionales y en circunstancias en las que el tribunal constitucional no ha tenido aún oportunidad de pronunciarse» ${ }^{16}$. Por tanto, sería válido afirmar que aunque la argumentación se enmarque, de una parte, en la justificación de los procesos interpretativos y, de otra parte, en la debida aplicación de la Constitución, es la ponderación quien le dota de una poderosa herramienta valorativa ante los conflictos entre principios constitucionales.

A pesar de todo, no cualquier ejercicio argumentativo-justificativo tiene su punto de soporte en las premisas equivalentes a valores y normas constitucionales, de manera que en los casos que no son difíciles no habría un fundamento alguno para realizarla, pues con la labor justificativa no se requiere llegar a un grado de profundidad mayor, como si se requeriría en los casos difíciles, esto es, en los casos ajenos a la aplicación de criterios tales como ley posterior sobre ley anterior y de ley superior sobre ley inferior, entre otros, donde, por ejemplo, la ponderación transportaría al juez a su doble esquema, axiológico y móvil.

Lo anterior, aun cuando sean características de los principios su imprecisión al estar formulados abiertamente y su contraposición respecto a la aplicación que podrían o no tener frente a una situación concreta. Con lo que aunque en la actualidad no haya un método que determine los pasos a seguir, para determinar un resultado favorable en estas situaciones, si hay una serie de criterios que de

16 Quien además señala que "cuando lo ha hecho, el juez ordinario tiene ya a su disposición una regla, esto es, debe seguir la ponderación efectuada por el tribunal constitucional". acuerdo a Atienza son guías a tener muy en cuenta, estos criterios «son característicos de cualquier argumentación práctica de carácter justificativo (...) y otros vinculados a una determinada concepción de la Constitución» (Atienza, p. 54), desde luego, del Derecho del Estado constitucional.

\section{REFERENCIAS}

Alexander, L. (2011). ¿What Should Constitutions Do? Social Philosophy and Policy, Cambridge: Cambridge University Press, 28.

Atienza, M. \& Ruíz, J. (2007). Dejemos atrás el positivismo jurídico. Isonomía: Revista de Teoría y Filosofía del Derecho, 27.

Berman, M. (2011). Constitutional Interpretation: Non-originalism. Philosophy Compass, 6/6.

Berman, M. (2010). Constitutional constructions and constitutional decision rules: thoughts on the Carving of Implementation Space. Constitutional Commentary, 1.

Bernal, C. (2006). The Rationality of Balancing, En: Steiner-Verlag, Franz (Ed.), Archiv Fur Rechts- Und Sozialphilosophie, v. 1.

Bouzat, G. (1998, Septiembre/Diciembre). La argumentación jurídica en el control constitucional. Revista Española de Derecho Constitucional, 54.

Comanducci, P. (2003). Formas de (neo)constitucionalismo. En Carbonell, M. (Eds.). Neoconstitucionalismo. Madrid: Trotta.

Duverger, M. (1970). Instituciones políticas y Derecho Constitucional. Barcelona: Ariel.

Dworkin, R. (2007). La Justicia con Toga. Madrid: Marcial Pons.

Dworkin, R. (2004). La Lectura Moral y la Premisa Mayoritaria. En Hongju, H. \& Slye, R. (Eds.). Democracia Deliberativa y Derechos Humanos, Barcelona: Gedisa.

Dworkin, R. (1993). Los derechos en serio. Buenos Aires: Planeta-Agostini. 
Etchichury, H. (2011). Poder judicial, democracia y derechos sociales. Revista Electrónica del Instituto de Investigaciones Jurídicas y Sociales «Ambrosio L. Gioja».

Friedman, B. (2005). Las posibilidades normativas del control de constitucionalidad: Una respuesta a Roberto Gargarella. Revista Jurídica de la Universidad de Palermo, 61.

Gargarella, R. (2008). Constitucionalismo vs. democracia. En Gargarella, R. (Eds.) Teoría y crítica del Derecho Constitucional. Buenos Aires: Abeledo Perrot.

Hamilton, A. (1788). Federalist papers. New York: Independent Journal, 78. Hayek, F. (1960). The Constitution of Liberty. Chicago, IL: University of Chicago Press.

Holmes, S. (2004). Precommitment and the Paradox of Democracy. En Elster, J. \& Slagstad, R. (Eds.), Constitucionalismo y democracia. Ciudad de México: Fondo de Cultura Económica.

Jefferson, T. (1984). Writings. New York: Library of America.

Kohn, C. (2000). Las paradojas de la democracia liberal: la ausencia del hombre en el Fin de la historia. Caracas: Exd.

Landau, D. (2011). Instituciones políticas y función judicial. Revista de Economía Institucional, 13, 24.

Pulido, F. (2012). Panorama de los problemas actuales en interpretación constitucional. Revista Díkaion, 21, 1.

Madison, J. (1961). The federalist. 48.

Martí, J. L. (2000). La República Deliberativa. Madrid: Marcial Pons.

Matheus, J. M. (2011). La disciplina parlamentaria. Pamplona: Universidad de Navarra,

Tushnet, M. (2001). Evaluating Congressional Constitucion Interpretation. Duke Law Journal.
Moreso, J. (2002). En defensa del positivismo jurídico inclusivo. En Navarro, P. \& Redondo, C. (Eds.). La relevancia del Derecho. Barcelona: Gedisa.

Moreso, J. (2003). Comanducci sobre neoconstitucionalismo. Isonomía: Revista de Teoría y Filosofía del Derecho, 19, 6.

Paine, T. (1791). The Rights of the Man. London: J.S. Jordan.Prieto, L. (1991). Notas sobre la interpretación constitucional. En Revista del Centro de Estudios Constitucionales y Políticos de Madrid, 9.

Pufendorf, S. (1934). De iure nature et gentium, Oxford: Clarendon Press.

Schmitt, C. (1928). Verfassungslere Berlin: Dunker and Humblot.

Shapiro, M. (1968). The Constitution of the United States and Related Documents. New York: Appleton-Century-Crofts.

Tushnet, M. (1992). Constitutional Interpretation, Character and Experience. Boston University Law Review, 72.

Tushnet, M. (2003). Alternative Forms of Judicial Review. En Michigan Law Review, 101.

Vigo, R. (2003). Balance de la teoría jurídica discursiva de Robert Alexy. Revista Doxa, 26.

Vigo, R. (2009). Argumentación Constitucional. Revista Iberoamericana de Derecho Procesal Constitucional, 12.

Waluchow, W. (2008). Constitutionalism. En Zalta, E. N. (Ed.) The Stanford Encyclopedia of Philosophy.

Waluchow, W. (2009). Una Teoría de Control Judicial de Constitucionalidad Basada en el Common Law. Madrid: Marcial Pons.

Waluchow, W. (2009). Una Teoría del Control Judicial de Constitucionalidad Basada en el 'Common Law'. Un árbol vivo. Madrid: Marcial Pons. 